Cite this: J. Anal. At. Spectrom., 2014, 29, 606

Received 15th October 2013 Accepted 5th December 2013 DOI: 10.1039/c3ja50340b www.rsc.org/jaas

\section{The expired breath carbon delta value is a marker for the onset of sepsis in a swine model}

\author{
Daniel E. Bütz, $\dagger^{\star * a}$ Samantha L. Morello, ${ }^{b}$ Jordan Sand, ${ }^{a}$ G. Neil Holland $\dagger^{c}$ \\ and Mark E. Cook $\dagger^{a}$
}

Approximately 750000 people develop sepsis each year with more than 215000 deaths. Earlier diagnosis and treatment of sepsis are critical to improving the outcome. The exhaled breath delta value (i.e. ${ }^{13} \mathrm{CO}_{2} /{ }^{12} \mathrm{CO}_{2}$ ratio, or BDV) is a biomarker for the acute phase response in sepsis models. The objective of this study was to define the temporal relationship between changes in the BDV, physiological and blood markers of sepsis in a porcine cecal ligation and puncture (CLP) model of sepsis. CLP led to a significant decrease in BDV in animals with stable mean arterial pressure during the course of the study, while the BDV of control animals was similar to that in animals that rapidly progressed into septic shock. The BDV indicated the onset of sepsis with a mean time of 3.54 hours (SEM 0.96) while physiological parameters detected the onset of sepsis in 11.11 hours (SEM 0.94) $(p<0.001)$. Biologic protein markers of inflammation (cytokines, including interleukin (IL)-13, IL-4, IL-12, granulocyte/macrophage colony stimulating factor, interferon-gamma, and transforming growth factor-beta) did not change significantly during the experiment. Tumor necrosis factor-alpha was present at the baseline, at 2 hours in the control and CLP group with falling blood pressure, and at 8 hours in the control group. IL- 6 was present at the baseline in all groups and spiked in the CLP animals with stable mean arterial pressure by 15 hours. The C-reactive protein was elevated in CLP and control animals by 8 hours $(p<0.05)$. Procalcitonin was present pre-surgery and increased above the baseline by 8 in CLP animals. These data show that the breath delta value is a leading indicator of sepsis in a porcine CLP model when compared to other physiological parameters.

\section{Introduction}

Sepsis and septic shock are leading causes of death in critically ill patients. Approximately 750000 people develop sepsis each year with more than 215000 people ultimately dying of septic shock. ${ }^{1}$ The US hospital mortality from sepsis ranges from $18 \%$ to $28 \%$ in adults, ${ }^{2}$ but increases to $30 \%$ in $65-69$ year olds and $38.4 \%$ in those older than 85 years. ${ }^{1}$ Sepsis is associated with the use of extensive healthcare resources. It is estimated that total costs exceed $\$ 16.7$ billion annually. ${ }^{1}$

Sepsis is defined as a systemic inflammatory response syndrome (SIRS) with a confirmed or suspected infection. ${ }^{3}$ SIRS is nonspecific and develops following a severe biological insult, such as infection, trauma, surgery, organ dysfunction, organ failure, an ischemic event or burns. In a prospective survey of adult patients admitted to a tertiary care center, $68 \%$ of

\footnotetext{
${ }^{a}$ Animal Science Department, College of Agricultural and Life Sciences, University of Wisconsin-Madison, WI, 53706,USA.E-mail: debutz@wisc.edu

${ }^{b}$ Department of Surgical Sciences, School of Veterinary Medicine, University of Wisconsin-Madison, WI, 53706, USA

'Isomark, LLC, Madison, WI, 53711, USA

$\dagger$ Authors D.E.B., G.N.H. and M.E.C. have ownership interest in Isomark, LLC, which has licensed the technology discussed in this publication.
}

admissions met SIRS criteria and 26\% developed sepsis. ${ }^{4}$ Trauma is frequently associated with SIRS ${ }^{5}$ and in the US 5.7\% patients admitted to the hospital after vehicular trauma develop an infection. ${ }^{6}$ Clinical data are often unreliable in distinguishing between patients with bacterial sepsis and those with SIRS secondary to a cause other than infection. Early detection of infections has clear implications for reducing both morbidity and mortality in the critically ill. ${ }^{7}$ The overdiagnosis of bacterial infection and associated unnecessary use of antibiotics may lead to antibiotic resistance and complications related to antibiotic exposure such as the increasing morbidity associated with hospital acquired infections. ${ }^{8}$ There is a clear and unmet need for a reliable method of early detection of bacterial sepsis in hospitalized patients.

There are several biomarkers potentially useful in the diagnosis of bacterial sepsis, but all of them have limitations. The white blood cell count and absolute neutrophil count are inexpensive but lack adequate sensitivity and specificity to detect serious bacterial infections. ${ }^{9}$ Cellular production of soluble proteins called cytokines, which function as pro-inflammatory mediators at the cellular level, is known to increase significantly during the early stages of acute inflammation; ${ }^{10}$ however, they do not provide a clinically efficient and cost effective method of 
detection. The C-reactive protein (CRP) assay is readily available and its determination is relatively inexpensive compared to the determination of procalcitonin (PCT) but it is not sensitive enough to detect severe bacterial infections early in the patient's clinical course. ${ }^{11}$ PCT outperforms CRP in the detection of bacterial infection, ${ }^{\mathbf{1 2}, 13}$ but determination of PCT is expensive and has had limited adoption in the US. Further, PCT can be non-specifically elevated in postoperative patients and those with burns, trauma, and other noninfectious causes of SIRS. ${ }^{11}$ Ideally, an infection biomarker would be sensitive, specific to infection, and could be measured continuously and noninvasively.

Carbon-12 and carbon-13 are naturally abundant isotopes in expired breath carbon dioxide. The breath ${ }^{13} \mathrm{CO}_{2} /{ }^{12} \mathrm{CO}_{2}$ delta value (BDV) has been shown to be a valuable biomarker of catabolic infectious states in different animal models of bacterial sepsis. ${ }^{\mathbf{1 4 , 1 5}}$ BDV begins dropping immediately after administration of a lipopolysaccharide (LPS) to experimental animals. ${ }^{15}$ Furthermore, the change in BDV precedes other physiological changes associated with infection, such as drop in the mean arterial pressure. ${ }^{\mathbf{1 4}}$ Recent advances in cavity enhanced infrared laser spectroscopy have enabled real-time continuous measurement of the BDV in the laboratory or at the point of care. ${ }^{16}$

The primary objective of this study was to define the temporal relationship between changes in the BDV, physiological signs of sepsis, plasma cytokines, CRP, and PCT in a porcine cecal ligation and puncture model of sepsis. If the BDV accurately discriminates the onset of sepsis earlier than other physiological markers, it may be a powerful biomarker for diagnosing life-threatening infections in critically ill patients.

\section{Experimental methods}

The University of Wisconsin-Madison College of Agricultural and Life Sciences Animal Care and Use Committee approved all animal procedures.

\section{Animals}

Thirty-five kilogram swine were obtained from the UW breeding colony in Arlington, WI, and brought (one at a time) to the catheterization lab at the UW-hospital where experimental procedures were conducted. Swine remained at the catheterization lab for the duration of the experiment. Swine were subjected to fasting overnight before the experiment with free access to water.

\section{Anesthesia and instrumentation}

Anesthesia was induced with tiletamine-zolazepam (Telazol, 4$6 \mathrm{mg} \mathrm{kg}^{-1}$, intramuscularly) and xylazine hydrochloride $(2.2 \mathrm{mg}$ $\mathrm{kg}^{-1}$, intramuscularly) to orally intubate the animal and establish positive pressure ventilation. Mechanical ventilation was required to ensure adequate oxygenation while the animals were anesthetized for the duration of the experiment, and to allow simple access to monitor exhaled air from the ventilator circuit. Propofol (4-20 mg kg ${ }^{-1}$, IV) was administered as needed to facilitate orotracheal intubation. Animals were ventilated at a constant tidal volume $\left(10-15 \mathrm{~mL} \mathrm{~kg}^{-1}\right)$ and rate $(14-18 \mathrm{bpm})$ in order to maintain an initial end-tidal $\mathrm{CO}_{2}$ of 33-35 mmHg. An intravenous catheter was established in an ear vein or other access point for infusion of additional drugs and fluid. A loading dose of pentobarbital (20 mg $\mathrm{kg}^{-1}$ ) followed by continuous rate infusion of pentobarbital $\left(10 \mathrm{mg} \mathrm{kg}^{-1} \mathrm{~h}^{-1}\right)$ was used to maintain anesthesia during the experimental period. Arterial and venous access catheters were placed percutaneously in either of the femoral or jugular vessels. If percutaneous access could not be achieved, the vessel was surgically isolated with a small cut down incision. Polyethylene tubing was introduced for invasive pressure monitoring (direct arterial blood pressure and central venous pressure) and blood sample access. A 7Fr triple lumen thermistor tip Swan-Ganz catheter was inserted via the femoral artery into the main pulmonary artery for measurement of cardiac output. To aid in the accurate placement of catheters, fluoroscopic X-ray imaging was used. Following access, 3000 units of heparin were given as an anticoagulant every hour.

\section{Vital sign monitoring}

Swine were monitored continuously for the duration of the experiment using a Vital-Guard 450C patient monitor. A 3-lead electrocardiographic monitor and pulse oximeter were placed. Monitored parameters were recorded every 15 minutes and included: temperature, heart rate, respiratory rate, mean arterial pressure (MAP), central venous pressure (CVP), electrocardiogram (ECG), blood oxygen saturation, and end tidal $\mathrm{CO}_{2}$. The exhaled BDV was monitored continuously from a side stream of the endotracheal tube. Blood glucose and cardiac output were measured and recorded every 30 minutes.

\section{Sepsis induction by cecal ligation and puncture (CLP)}

After instrumentation animals were allowed to stabilize. Following this, midline laparotomy was performed. The cecum was identified, exteriorized, and circumferentially ligated $8 \mathrm{~cm}$ proximal to the apex with non-absorbable suture material. A 1 $\mathrm{cm}$ incision was made at the apex to allow leakage of fermenting intestinal contents, and the cecum was replaced in the abdominal cavity. The time of cecal perforation was considered to be zero for the experiment. The laparotomy incision was closed in two layers. Control animals underwent laparotomy with cecal manipulation, but no ligation or puncture, and thus no infection. The vital parameters described above were monitored continuously for up to 15 hours or until death. During the sepsis period, animals were maintained on isotonic fluids at a maintenance rate $2.5 \mathrm{mg} \mathrm{kg}^{-1} \mathrm{~h}^{-1}$. Fluid boluses of $500 \mathrm{~mL}$ (over a 30 minute period) were administered only if one or more of the following criteria was met: (1) central venous pressure values decreased to less than $10 \mathrm{mmHg}$ and (2) mean arterial pressure decreased to less than $70 \mathrm{mmHg}$. Experiments were terminated when the mean arterial pressure fell below $60 \mathrm{mmHg}$ and did not respond to fluid support. 


\section{Expired BDV monitoring}

Wavelength-scanned cavity ring-down spectroscopy (WS-CRDS) is a well-established technique for detecting trace quantities of gases. ${ }^{17,18}$ The key element in WS-CRDS is a precisely aligned optical cavity with three very high reflectance mirrors (>99.995\%). Briefly, when light from a continuous wave laser that matches the resonance frequency of the cavity enters the cavity, the energy levels in the cavity increase over time. When the laser is turned off, the energy decays ("rings down") exponentially over microseconds; this decay is measured using a photodiode. WS-CRDS measures the length of the ring down time over different wavelengths, because the laser is tuned for the analyte gas' molecular signature. A strongly absorbing gas will have a relatively short ring down time compared to the empty cavity. Each gas has its characteristic concentrationdependent ring-down time at different wavelengths. Fig. 1 depicts a ring-down curve, showing the changing light intensity inside the cavity as a function of time after the incident laser is shut off. WS-CRDS generates a detailed profile, area and height of an individual absorption, Fig. 2, panel A. The ${ }^{13} \mathrm{CO}_{2}$ delta value is determined by scanning the absorption frequency features for ${ }^{13} \mathrm{CO}_{2}$ and ${ }^{12} \mathrm{CO}_{2}$ separately and calculating the value referenced to Pee Dee Belemnite (PDB). Data are expressed as delta values or parts per mil $(\%)$ :

$$
\delta=\frac{{ }^{13} \mathrm{CO}_{2} /{ }^{12} \mathrm{CO}_{2}(\text { sample })-{ }^{13} \mathrm{CO}_{2} /{ }^{12} \mathrm{CO}_{2}(\mathrm{PDB})}{{ }^{13} \mathrm{CO}_{2} /{ }^{12} \mathrm{CO}_{2}(\mathrm{PDB})} \times 1000
$$

The precision obtained for ${ }^{13} \mathrm{CO}_{2} /{ }^{12} \mathrm{CO}_{2}$ using the WS-CRDS technique is better than $0.3 \%$ with $\mathrm{CO}_{2}$ concentrations between 380 and $500 \mathrm{ppm} \mathrm{CO}_{2}$ corresponding to a $10 \mathrm{ppb}^{13} \mathrm{CO}_{2}$ and 200 ppb ${ }^{12} \mathrm{CO}_{2}$ limit of detection. Fig. 2, panel $\mathrm{B}$ depicts isotopic precision (in box plots) WS-CRDS for determination of isotope ratios of two $5 \% \mathrm{CO}_{2}$ reference gases (Cambridge Isotope Labs, Tewksbury, MA) diluted to $400 \mathrm{ppm} \mathrm{CO}_{2}$.

During breath sampling, exhaust air was sampled via a side stream T-joint and introduced into a breath dilution system (Isomark, LLC, Madison, WI, USA), where the animals' breath was diluted to 400 ppmv $\mathrm{CO}_{2}$ using air containing less than $0.001 \% \mathrm{CO}_{2}$. The diluted breath was introduced into an isotopic $\mathrm{CO}_{2}$ cavity ring-down spectrometer (CRDS, Picarro, Sunnyvale,

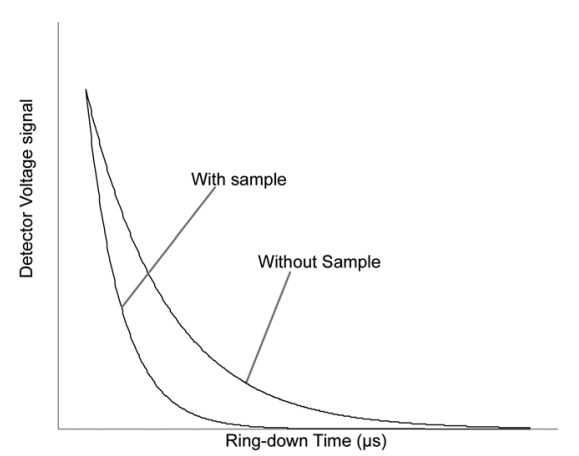

Fig. 1 Ring-down trace showing exponential decay of the optical signal with and without analyte gas.
B
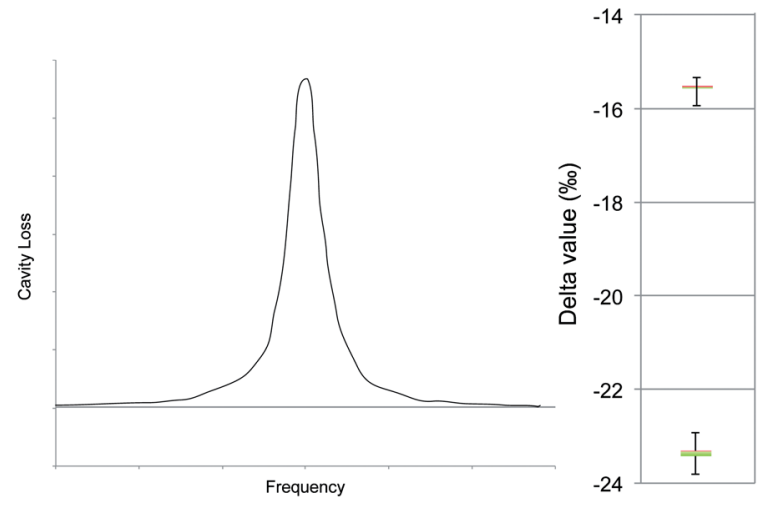

Fig. 2 Panel A: loss spectrum from WS-CRDS. The curve represents the cavity loss over a spectral line for a single analyte, for example ${ }^{13} \mathrm{CO}_{2}$. Panel $\mathrm{B}$ : box plot of the analyzer delta value precision for two reference samples.

CA, USA) where the BDV was continuously determined at a sampling rate of approximately 1 determination per second. To increase accuracy we signal averaged the data for 5 minutes using a boxcar strategy. Data that are signal averaged for 5 minutes are precise to better than $0.3 \%$.

\section{Plasma biomarker analysis}

Blood was collected from the venous catheter line at time zero, 2 hours, 8 hours and 15 hours in $3 \mathrm{~mL}$ heparinized green top Vacutaners and placed on ice. Blood was centrifuged at $3000 \mathrm{~g}$ for 10 minutes at $4{ }^{\circ} \mathrm{C}$. Plasma was transferred to new tubes and stored at $-80{ }^{\circ} \mathrm{C}$ until analysis. A number of cytokines, interleukin-1 $\beta$ (IL-1 $\beta$ ), IL-4 IL-6, IL-8, IL-10, IL-12, granulocyte/ macrophage-colony stimulating factor (GM-CSF), interferon- $\gamma$ (INF- $\gamma$ ), transforming growth factor- $\beta$ (TGF- $\beta$ ) and tumor necrosis factor- $\alpha$ (TNF- $\alpha$ ) were determined using a porcine cytokine Quantibody multiplex assay kit (RayBiotech, Norcross, GA, USA) according to the manufacturer's instructions. Briefly, Quantibody slides were allowed to equilibrate to room temperature before $100 \mu \mathrm{L}$ of sample buffer was added to each well for 30 minutes. The sample buffer was decanted and $100 \mu \mathrm{L}$ of sample or cytokine standard was added to the plate and incubated at room temperature for 2 hours. The samples were decanted and the plate was washed 5 times with the supplied wash buffer. The biotin conjugated detection antibody cocktail was reconstituted with sample buffer and $80 \mu \mathrm{L}$ was added to each well. The plate was incubated for 2 hours and washed as before. The streptavidin conjugated Cy3 dye was reconstituted with sample buffer and $80 \mu \mathrm{L}$ was added to each well, and the apparatus was covered in aluminum foil to exclude light and incubated at room temperature for 1 hour. The wells were washed 5 times as before. The glass slides were then removed from the well apparatus by carefully removing the clips and wells from the glass slide. The individual slides were then gently washed in the supplied washer/dryer tube and dried by decanting all of the wash buffer and centrifuging the drying 
apparatus at $1000 \mathrm{rpm}$ for 3 minutes. Slide images were generated on an AXON GenePix imager (Fig. 5). The limits of detection are shown in Table 1. Plasma PCT and CRP were determined using an enzyme linked immunosorbent assay (ELISA) kit according to the manufacturer's instructions (TSZ ELISA, Waltham, MA, USA; GenWay Biotech, San Diego, CA, USA, respectively). Briefly, $100 \mu \mathrm{L}$ of undiluted plasma sample was added to each well of 96 well plates pre-coated with either PCT or CRP and incubated at room temperature for 2 hours. The plate was washed 5 times with phosphate buffered saline containing 5\% Tween-20. Horseradish peroxidase linked detection antibodies were added to each well and incubated at room temperature for 1 hour. The plate was washed 7 times. The substrate solution containing tetramethylbenzidine (TMB) and hydrogen peroxide was added to the plate and incubated for exactly 15 minutes prior to addition of $1 \mathrm{M} \mathrm{H}_{3} \mathrm{PO}_{4}$ to stop the reaction. The optical density was read at $450 \mathrm{~nm}$ with a reference wavelength of $600 \mathrm{~nm}$. The sample concentration was calculated based on a standard curve, generated using known concentrations of either PCT or CRP. The limits of detection for PCT and CRP are shown in Table 1.

\section{Statistical analysis}

The mean and standard errors were calculated for each parameter. Statistical analysis was done using an analysis of variance (ANOVA) for the physiological parameters including heart rate, mean arterial pressure, central venous pressure, body temperature, glucose, IL-1 $\beta$, IL-4, IL-6, IL-12, GM-CSF, INF $\gamma, \mathrm{TGF} \beta 1$, and TNF $\alpha$ to determine if there was any difference between the control operation and CLP animals. BDV and MAP were plotted over time and the linear trend line was calculated for each subject. Due to a known interaction between BDV and poor tissue oxygenation, as indicated by an abnormally negative slope in the MAP trend, ${ }^{\mathbf{1 4 , 1 9 - 2 3}}$ animals with an abnormally negative MAP slope were considered separately from CLP animals with a stable MAP. ANOVA with least significant difference post-hoc analysis was applied to the slope of the line for each group. Previous work demonstrated that a decrease in the exhaled BDV correlated with an inflammatory response to infection within an animal. ${ }^{\mathbf{1 4 , 1 5}}$ We calculated the mean time to positive indication of infection by the $\mathrm{BDV}(>1 \%$ decrease in

Table 1 Limit of detection for blood markers

\begin{tabular}{ll}
\hline Cytokine & Limit of detection \\
\hline IL-1 $\beta$ & $14 \mathrm{pg} \mathrm{mL}^{-1}$ \\
IL-4 & $5 \mathrm{pg} \mathrm{mL}{ }^{-1}$ \\
IL-6 & $3 \mathrm{pg} \mathrm{mL}$ \\
IL-8 & $5 \mathrm{pg} \mathrm{mL}$ \\
IL-10 & $14 \mathrm{pg} \mathrm{mL}^{-1}$ \\
IL-12 & $137 \mathrm{pg} \mathrm{mL}^{-1}$ \\
GM-CSF & $55 \mathrm{pg} \mathrm{mL}^{-1}$ \\
INF- $\gamma$ & $27 \mathrm{pg} \mathrm{mL}^{-1}$ \\
TGF- $\beta$ & $27 \mathrm{pg} \mathrm{mL}^{-1}$ \\
TNF- $\alpha$ & $137 \mathrm{pg} \mathrm{mL}^{-1}$ \\
CRP & $6.25 \mathrm{ng} \mathrm{mL}^{-1}$ \\
PCT & $0.312 \mathrm{ng} \mathrm{mL}^{-1}$
\end{tabular}

BDV) and SIRS criteria. SIRS was defined by meeting least two of the following: tachycardia ( $>150$ beats per minute) and hyper- or hypothermia $\left(>40.5{ }^{\circ} \mathrm{C}\right.$ or $\left.<37^{\circ} \mathrm{C}\right)$. The mean time to a positive indication of infection by BDV and SIRS criteria was compared using a Student's $t$-test. Specificity and sensitivity were calculated using the false positive and false negative rates for BDV and SIRS. Differences were considered with a $p$-value $<0.05$.

\section{Results}

We induced a polymicrobial sepsis in $35 \mathrm{~kg}$ swine using CLP methodology. Fig. 3 shows the survival rate of animals during the experiment. All control animals survived for the 15-hour duration of the experiment, while two CLP animals failed to respond to fluid resuscitation and met end point criteria at 10.25 hours and 14 hours after surgery. Mechanical equipment failure caused termination of one CLP animal after only 8 hours. Since septic shock with low MAP can have a significant impact on the $\mathrm{BDV}^{\mathbf{1 4 , 1 9 - 2 3}}$ we considered animals with an abnormally rapid decline in MAP (CLPFM) separately from animals that had normal MAP (CLPNM). Fig. 4 shows MAP (panel A) and BDV (panel B) over time. The CLP procedure caused a significant drop in the BDV in CLPNM animals. The slope of the line from a linear trend analysis shows a significant decline in the BDV in the CLPNM as compared with control animals $(p=0.03)$. The slope of the line was positive in CLPFM animals and not different from the control $(p=0.15)$. In all CLP animals, the BDV provided evidence for the onset of infection in 3.54 (SEM 0.96) hours which was significantly faster than the 11.11 (SEM 0.94) hours it took for SIRS criteria to detect infection $(p<0.001)$.

The cardiac output was significantly lower in CLPFM animals than in control animals by 2 hours and by 8 hours in CLPNM animals (Table $2 ; p<0.05$ ). By 8 hours CLPFM animals had reduced body temperature, cardiac output, and end tidal $\mathrm{CO}_{2}$. By 15 hours CLPNM animals were significantly more

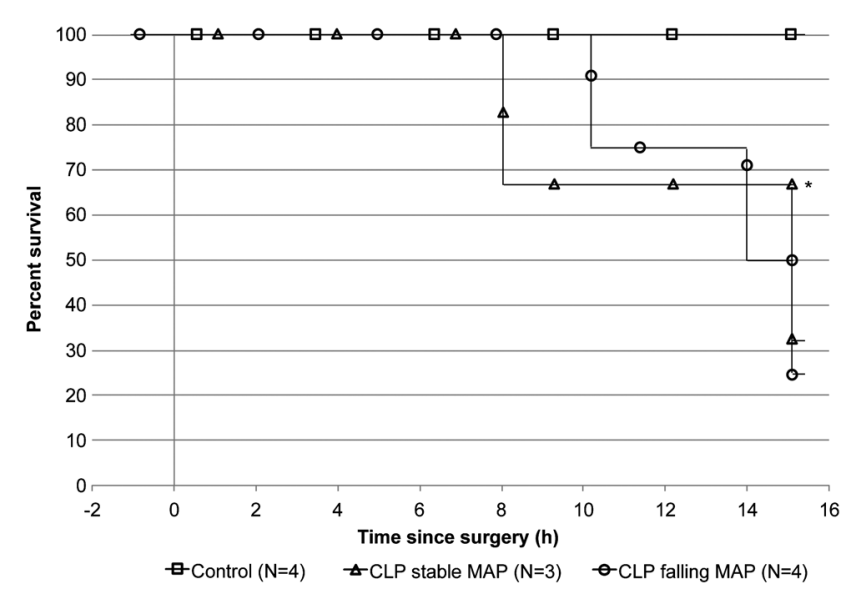

Fig. 3 Percentage survival after cecal ligation and puncture (CLP) surgery in pigs. The end point criterion was a mean arterial pressure (MAP) below $60 \mathrm{mmHg}$ that failed to respond to fluid resuscitation. * One animal in the CLP with a stable MAP group was terminated early due to equipment malfunction. 


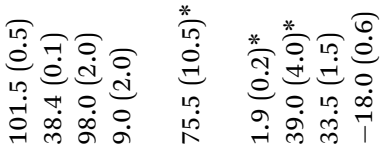

$\stackrel{*}{\infty}$

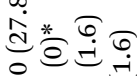

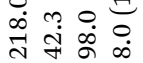

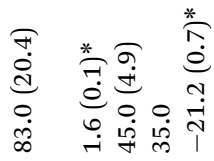

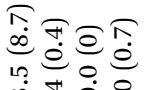

ம்

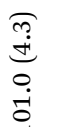

ণู่

10

*

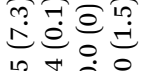

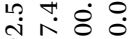

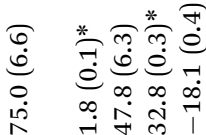

ન.

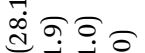

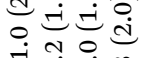

ले

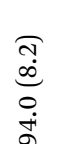

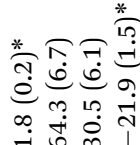

สุ่

वृ?

숭ํำ

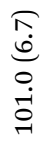

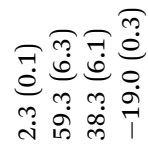

เกติอ

ôj 000

官

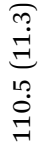

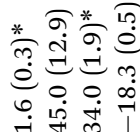

tachycardic than control animals, with an elevated body temperature $(p<0.05)$ and reduced cardiac output (Table $2 ; p<$ $0.05)$. IL-1 $\beta$, IL-4, IL-12, GM-CSF, INF $\gamma$, and TGF $\beta$ were detectable in blood plasma pre-surgery and did not change significantly during the experiment (Table 3). TNF $\alpha$ was present at the baseline, at 2 hours in the control and CLPFM groups, and at 8 hours in the control group (Table 3). IL-6 was present at a baseline level for all groups throughout the experiment and spiked from $24 \mathrm{pg} \mathrm{mL}^{-1}$ to $81 \mathrm{pg} \mathrm{mL}^{-1}$ in the CLPNM group by 15 hours (Table $3 ; p<0.05$ ). CRP was present at a baseline level in all groups until 8 hours when it increased in the control and CLPNM groups compared with pre-surgery values (Table $3 ; p<$ 0.05). PCT was present to a variable extent in the pre-surgery samples $\left(\right.$ mean $\left.=2.53 \mathrm{ng} \mathrm{mL}^{-1}\right)$, $\min =1.11, \max =4.01$, and increased above the baseline by $0.62 \mathrm{ng} \mathrm{mL}^{-1}(0.12 \mathrm{SEM})$ and $0.60 \mathrm{ng} \mathrm{mL}{ }^{-1}(0.08 \mathrm{SEM})$ at 8 and 15 hours, respectively, in both CLPNM and CLPFM animals.

\section{Discussion}

These data indicate that the BDV trend was a leading indicator for the onset of sepsis in swine following CLP when compared with other physiological parameters and blood biomarkers. The BDV detected the onset of sepsis in 3-4 hours after CLP while the SIRS criteria did not indicate an infection until a mean of 11 hours of sepsis. Nosocomial infections leading to sepsis are a leading cause of morbidity and mortality in the ICU. The mean time to diagnosis is 8 to 10 days for nosocomial infections in adult and pediatric trauma patients. ${ }^{24-26}$ Earlier diagnosis and treatment of infections will significantly reduce patient morbidity and mortality and reduce hospitalization costs. The data presented in this paper demonstrate that the BDV may be an early warning of infection that may be used as an adjunct marker for the earlier diagnosis of infection in critically ill patients.

While the BDV was a leading indicator in animals with a normal MAP, animals with a falling MAP trend tended to develop other physiological signs of infection earlier and progress to the endpoint criteria faster. In animals with a falling MAP trend, a depressed cardiac output was evident by 2 hours. By comparison, animals with a stable MAP were not different from control animals until 8 hours when the cardiac output was reduced while other physiological parameters were not different until 15 hours. In previous studies, animals with a falling MAP trend proceeded to meet the endpoint criteria faster than those with normal arterial pressures, ${ }^{15}$ perhaps because the disease is more severe in these animals or because these animals are naturally more susceptible to disease. During the early, compensatory stage of shock, the body is able to compensate for hypoperfusion using physiological mechanisms including neural, hormonal, and biochemical signals. As the acute phase response becomes more severe, the compensatory mechanisms are overwhelmed, and systemic circulation is compromised. During this decompensatory phase, alterations in the hemodynamic state that depresses the systemic blood pressure preferentially perfuse the vital organs, such as the heart and the central nervous system. Perfusion of the peripheral tissues or 
Table 3 Plasma biomarker profile following cecal ligation and puncture ${ }^{a}$

\begin{tabular}{|c|c|c|c|c|c|c|c|c|c|c|}
\hline & \multirow[b]{2}{*}{ Pre-surgery } & \multicolumn{3}{|l|}{2 hours } & \multicolumn{3}{|l|}{8 hours } & \multicolumn{3}{|l|}{15 hours } \\
\hline & & $\begin{array}{l}\text { Control } \\
\text { operated }\end{array}$ & $\begin{array}{l}\text { CLP stable } \\
\text { MAP }\end{array}$ & $\begin{array}{l}\text { CLP falling } \\
\text { MAP }\end{array}$ & $\begin{array}{l}\text { Control } \\
\text { operated }\end{array}$ & $\begin{array}{l}\text { CLP stable } \\
\text { MAP }\end{array}$ & $\begin{array}{l}\text { CLP falling } \\
\text { MAP }\end{array}$ & $\begin{array}{l}\text { Control } \\
\text { operated }\end{array}$ & $\begin{array}{l}\text { CLP stable } \\
\text { MAP }\end{array}$ & $\begin{array}{l}\text { CLP falling } \\
\text { MAP }\end{array}$ \\
\hline $\mathrm{IL}-1 \mathrm{~b}\left(\mathrm{pg} \mathrm{mL}^{-1}\right)$ & $370(440)$ & $360(180)$ & $220(24)$ & $610(680)$ & $370(140)$ & $\mathrm{N} / \mathrm{D}$ & $520(470)$ & $400(150)$ & $210(3)$ & N/A \\
\hline $\mathrm{IL}-4\left(\mathrm{ng} \mathrm{mL}^{-1}\right)$ & $2.1(1.7)$ & $1.6(1.5)$ & $1.9(1)$ & $4(2.2)$ & $2.6(3.4)$ & $1.3(1)$ & $4(2.5)$ & $1.9(2.3)$ & $1.2(1.1)$ & N/A \\
\hline IL-6 $(\mathrm{pg} \mathrm{mL}-1)$ & $33(40)$ & $10(7)$ & $24(17)$ & $94(71)$ & $15(11)$ & $43(28)$ & $62(46)$ & $9(5)$ & $81(17)^{*}$ & N/A \\
\hline $\operatorname{IFNg}\left(\mathrm{ng} \mathrm{mL}^{-1}\right)$ & $0.8(0.6)$ & $1.3(0.4)$ & $0.7(0.4)$ & N/D & $1(0.2)$ & $0.4(0.4)$ & $\mathrm{N} / \mathrm{D}$ & $0.9(0.5)$ & N/D & N/A \\
\hline TGFb1 (ng mL $\left.{ }^{-1}\right)$ & $8.2(7.7)$ & $8.5(6)$ & $4.6(2)$ & $14(14)$ & $7.9(7)$ & $4.2(2.7)$ & $7(5.2)$ & $8.2(6.7)$ & $3.8(3.6)$ & N/A \\
\hline $\begin{array}{l}\text { C-reactive protein } \\
\left(\mathrm{ng} \mathrm{mL} \mathrm{mL}^{-1}\right)\end{array}$ & $52(56)$ & $90.2(94)$ & $36.7(16)$ & $36(11)$ & $130(90)^{* *}$ & $75(54)^{* *}$ & $48.9(11)$ & $140.8(87)^{* *}$ & $181.1(56)^{* *}$ & N/A \\
\hline TNFa $\left(\mathrm{pg} \mathrm{mL}^{-1}\right)$ & $460(380)$ & $250(132)$ & N/D & 620 & $270(190)$ & $\mathrm{N} / \mathrm{D}$ & N/D & N/D & N/D & N/A \\
\hline
\end{tabular}

${ }^{a}$ Value $=$ mean (standard deviation). $\mathrm{N} / \mathrm{D}=$ not detectable. ${ }^{*}=p<0.01 v$ s. control. ${ }^{* *}=p<0.05 v s$. pre-surgery. N/A $=$ not applicable, data not available because only one animal was still alive at this time-point.

non-essential organs is compromised, causing relative ischemia.

During the decompensatory phase of septic shock, there is a significant shift in macronutrient oxidation and peripheral tissues utilize oxidation poorly even in an abundant supply. ${ }^{27,28}$ The net result is that lipid oxidation is reduced in favor of anaerobic glycolysis and lactate production. ${ }^{29}$ Alterations in macronutrient oxidation (i.e. altering the ratio of lipids versus protein and carbohydrate ratio) cause significant shifts in the BDV. ${ }^{19,20}$ Due to discrimination against ${ }^{13} \mathrm{C}$ by pyruvate dehydrogenase lipids are isotopically lighter than either protein or carbohydrate. ${ }^{30}$ Reduced lipid oxidation in animals with poor tissue perfusion drives the BDV in a positive direction. Animals that had a falling MAP quickly progressed from sepsis to septic shock. Thus, the BDV in animals with falling MAP may not present differently than in control animals as seen in Fig. 4. These data are consistent with findings from a rat peritonitis model $^{\mathbf{1 4}}$ and recent findings from a pilot study in pediatric patients with sepsis and septic shock. ${ }^{31}$ In both examples, patients with sepsis that progressed rapidly into septic shock exhibited a BDV that was initially very negative $(\sim-25 \%)$, that then progressed in a positive direction, ultimately becoming more positive than control or control subjects. While the BDV can be observed to increase during the transition to septic shock, this observation may be of limited use since the disease has progressed to a critical state before this trend would become evident.

The results of this study can be explained in part by the paradigm proposed in Fig. 6. The paradigm postulates that during the early acute phase response the BDV is inversely related to the severity of trauma and, to a greater extent, a developing infection. This proposed relationship is related to discrimination against ${ }^{13} \mathrm{C}$ during the oxidation of amino acids released from peripheral tissues during the acute phase response. ${ }^{15,31}$ However, as patients progress from sepsis to septic shock and the decompensatory phase of the process, alterations in macronutrient ratios begin to dominate the BDV signal resulting in a rapid increase in BDV. Thus, patients who have gone through septic shock can have near normal BDVs.
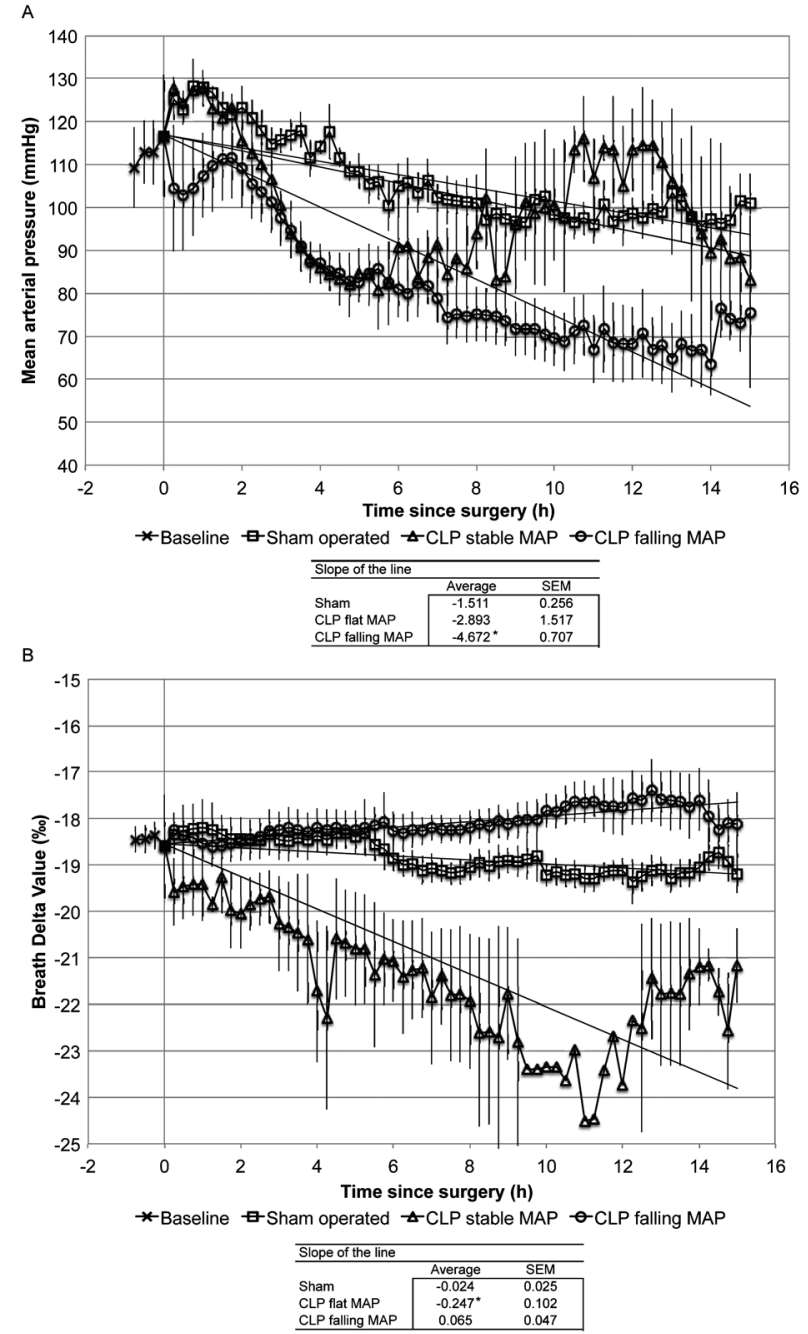

Fig. 4 Trend analysis of mean arterial pressure (MAP; panel A) and breath delta value (panel B). Cecal ligation and puncture (CLP) or control surgery was performed at time zero. Measurements were made once every 15 minutes. The mean and standard error of the mean were plotted. The linear trend line was calculated for each subject. ANOVA with least significant difference post-hoc analysis was applied to the slope of the line for each group. Asterisks denote significant differences with $p<0.05$. 

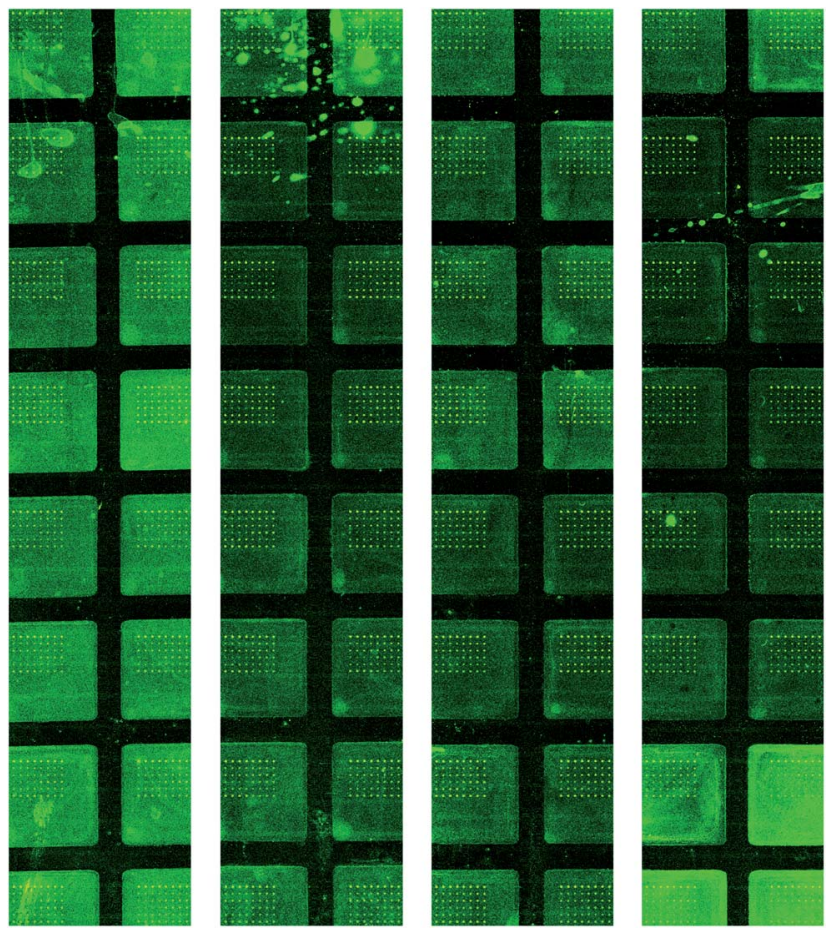

Fig. 5 Quantibody porcine cytokine microarray images. While the signal to noise ratio was within the manufacturer's specifications the random background noise may contribute to spurious results.

While the breath and physiology data generated in this study are consistent with the literature, ${ }^{\mathbf{1 4 , 1 5 , 3 2}}$ one of the limitations of this study is that limited reliable data were obtained from blood samples. Blood cytokines (i.e. IL-1 $\beta$, IL-4, IL-6, IL-12, GM-CSF, INF $\gamma$, TGF $\beta 1$, and TNF $\alpha$ ) are expected to change in response to inflammation. ${ }^{\mathbf{1 0 , 3 3}}$ We determined the blood cytokines using the Quantibody multiplex array from RayBiotech. The assay is based on antibody cytokine detection similar to enzyme linked immunosorbent assays where capture antibodies are spotted onto a glass slide. It appears that the assay is susceptible to background noise on the slides during detection. Fig. 5 shows the raw data from our cytokine multiplex assay. This observation may explain why the plasma cytokines seem highly variable in Table 3. While we did measure PCT in plasma samples, there was a highly variable baseline level of PCT which is a finding consistent with the literature. ${ }^{34}$ The PCT increases over the baseline by 8 hours in individual CLP animals as expected, ${ }^{35}$ but the increase in PCT (mean of $0.62 \mathrm{ng} \mathrm{mL} \mathrm{m}^{-1}$ increase over the baseline at 8 hours) was small compared to the inter-individual variation (SD of $1.19 \mathrm{ng} \mathrm{mL} \mathrm{mL}^{-1}$ at the baseline). Other studies have shown an increase in PCT from 8 to 10 hours after autologous feces injection or CLP. ${ }^{35,36}$ The possible reasons for high variability in the PCT measurement in this study include technical errors in sample processing or measurement, pre-existing exogenous stress, or the endogenous response to trauma during instrumentation.

Despite the high background noise in the cytokine data we did observe that IL-6 was elevated by 15 hours in septic animals which is consistent with previous findings. ${ }^{37}$ We also observed

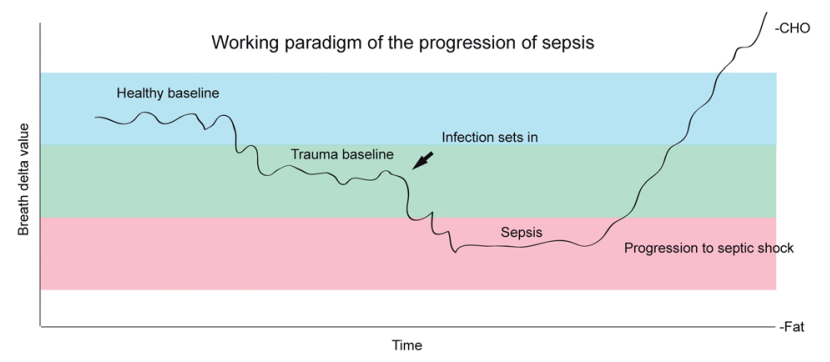

Fig. 6 Working paradigm of the transition from normal through trauma to sepsis and the progression through septic shock.

an increased CRP in both control and septic animals at the 8 and 15-hour time points. These data are consistent with the literature since CRP is a non-specific marker for inflammation and may be expected at increased levels following trauma, burns, surgery and inflammatory events. ${ }^{11,38}$

\section{Conclusions}

Sepsis leading to septic shock is a major cause of mortality in adult and pediatric intensive care units. ${ }^{1}$ Early detection and prompt treatment of sepsis are critical for survival and optimal outcomes. ${ }^{39,40}$ Growing evidence suggests that the BDV is a sensitive marker of the acute phase response. Since the BDV begins changing at the vary earliest stages of sepsis, and it changes well before other physiologic and blood markers, it may be considered an early indicator of the onset of infection and thus may be of some clinical utility for earlier detection of infections.

\section{References}

1 D. C. Angus, W. T. Linde-Zwirble, J. Lidicker, G. Clermont, J. Carcillo and M. R. Pinsky, Crit. Care Med., 2001, 29, 1303-1310.

2 K. E. Hodgin and M. Moss, Curr. Pharm. Des., 2008, 14, 18331839.

3 R. C. Bone, R. A. Balk, F. B. Cerra, R. P. Dellinger, A. M. Fein, W. A. Knaus, R. M. Schein and W. J. Sibbald, Chest., 1992, 101(6), 1644-1655.

4 M. S. Rangel-Frausto, D. Pittet, M. Costigan, T. Hwang, C. S. Davis and R. P. Wenzel, JAMA, J. Am. Med. Assoc., 1995, 273, 117-123.

5 A. Lenz, G. A. Franklin and W. G. Cheadle, Injury, 2007, 38, 1336-1345.

6 D. R. Fraser, V. Y. Dombrovskiy and T. R. Vogel, Surgical Infections, 2011, 12, 291-296.

7 E. P. Rivers, M. Katranji, K. A. Jaehne, S. Brown, G. A. Dagher, C. Cannon and V. Coba, Minerva Anestesiol., 2012.

8 J. Chastre, Clin. Microbiol. Infect., 2008, 3(14 suppl), 3-14.

9 B. Andreola, S. Bressan, S. Callegaro, A. Liverani, M. Plebani and L. Da Dalt, Pediatr. Infect. Dis. J., 2007, 26, 672-677.

10 R. J. Baigrie, P. M. Lamont, D. Kwiatkowski, M. J. Dallman and P. J. Morris, Br. J. Surg., 1992, 79, 757-760. 
11 J. N. Deis, C. B. Creech, C. M. Estrada and T. J. Abramo, Pediatric Emergency Medicine, 2010, 26, 51-60.

12 L. Simon, F. Gauvin, D. K. Amre, P. Saint-Louis and J. Lacroix, Clin. Infect. Dis., 2004, 39, 206-217.

13 M. Hatherill, S. M. Tibby, K. Sykes, C. Turner and I. A. Murdoch, Arch. Dis. Child., 1999, 81, 417-421.

14 D. E. Butz, M. E. Cook, W. P. Porter and F. Assadi-Porter, FASEB J., 2010, 24, 752.4.

15 D. E. Butz, M. E. Cook, H. R. Eghbalnia, F. Assadi-Porter and W. P. Porter, Rapid Commun. Mass Spectrom., 2009, 23, 37293735.

16 E. H. Wahl, B. Fidric, C. W. Rella, S. Koulikov, B. Kharlamov, S. Tan, A. A. Kachanov, B. A. Richman, E. R. Crosson, B. A. Paldus, S. Kalaskar and D. R. Bowling, Isot. Environ. Health Stud., 2006, 42, 21-35.

17 J. J. Scherer, J. B. Paul, A. O'Keefe and R. J. Saykally, Chem. Rev., 1997, 97(1), 25-52.

18 E. R. Crosson, Appl. Phys. B: Lasers Opt., 2008, 92, 403-408.

19 D. A. Schoeller, C. Brown, K. Nakamura, A. Nakagawa, R. S. Mazzeo, G. A. Brooks and T. F. Budinger, Biomed. Mass Spectrom., 1984, 11, 557-561.

20 K. A. Hatch, B. Pinshow and J. R. Speakman, J. Comp. Physiol., B, 2002, 172, 263-268.

21 R. P. Dellinger, Crit. Care Med., 2003, 31, 946-955.

22 D. E. Butz, S. L. Morello, J. Sand, J. P. Boriosi, G. N. Holland and M. E. Cook, FASEB J., 2013, 27, 868.5.

23 J. J. Spitzer, Circ. Shock. Suppl., 1979, 1, 69-79.

24 C. Bell and S. T. Coleridge, J. Emerg. Med., 1992, 10, 275-280.

25 M. Urrea, F. Torner, M. Pons, C. Latorre and R. Huguet, J. Pediatr. Orthop. B, 2005, 14, 371-374.

26 G. V. Bochicchio, K. M. Bochicchio, M. Joshi, O. Ilahi and T. M. Scalea, Ann. Surg., 2010, 252, 597-602.

27 B. Levy, L. O. Sadoune, A. M. Gelot, P. E. Bollaert, P. Nabet and A. Larcan, Crit. Care Med., 2000, 28, 114-119.

28 E. Rivers, B. Nguyen, S. Havstad, J. Ressler, A. Muzzin, B. Knoblich, E. Peterson and M. Tomlanovich, N. Engl. J. Med., 2001, 345, 1368-1377.
29 J. P. Revelly, L. Tappy, A. Martinez, M. Bollmann, M. C. Cayeux, M. M. Berger and R. L. Chiolero, Crit. Care Med., 2005, 33, 2235-2240.

30 M. J. DeNiro and S. Epstein, Science, 1977, 197, 261-263.

31 J. P. Boriosi, D. G. Maki, R. A. Yngsdal-Krenz, E. R. Wald, W. P. Porter, M. E. Cook and D. E. Butz, J. Anal. At. Spectrom., 2014, DOI: 10.1039/C3JA50331C.

32 E. Kieslichova, M. Rocen, D. Merta, M. Kudla, I. Splichal, J. Cap, O. Viklicky and R. Gurlich, Transplant. Proc., 2013, 45, 770-777.

33 T. van der Poll, R. de Waal Malefyt, S. M. Coyle and S. F. Lowry, J. Infect. Dis., 1997, 175, 118-122.

34 D. Annane, V. Maxime, J. P. Faller, C. Mezher, C. Clec'h, P. Martel, H. Gonzales, M. Feissel, Y. Cohen, G. Capellier, M. Gharbi and O. Nardi, BMJ open, 2013, 3, DOI: 10.1136/ bmjopen-2012-002186.

35 G. Chatzimavroudis, T. E. Pavlidis, I. Koutelidakis, E. J. Giamarrelos-Bourboulis, S. Atmatzidis, K. Kontopoulou, G. Marakis and K. Atmatzidis, J. Surg. Res., 2009, 152, 69-75.

36 J. M. Martinez, K. E. Wagner, R. H. Snider, E. S. Nylen, B. Muller, B. Sarani, K. L. Becker and J. C. White, Surgical Infections, 2001, 2, 193-202; Discussion, 202-193.

37 H. Zhu, S. Wang, L. Shen, W. Wang, F. Zhao and T. Cao, Int. Immunopharmacol., 2013, 17, 836-842.

38 E. M. Clary, S. M. Bruch, C. L. Lau, A. Ali, E. G. Chekan, M. J. Garcia-Oria and S. Eubanks, J. Surg. Res., 2002, 108, 32-38.

39 A. E. Jones, A. Focht, J. M. Horton and J. A. Kline, Chest, 2007, 132, 425-432.

40 R. P. Dellinger, M. M. Levy, J. M. Carlet, J. Bion, M. M. Parker, R. Jaeschke, K. Reinhart, D. C. Angus, C. Brun-Buisson, R. Beale, T. Calandra, J. F. Dhainaut, H. Gerlach, M. Harvey, J. J. Marini, J. Marshall, M. Ranieri, G. Ramsay, J. Sevransky, B. T. Thompson, S. Townsend, J. S. Vender, J. L. Zimmerman and J. L. Vincent, Crit. Care Med., 2008, 36, 296-327. 